\title{
Integration of theory courses and design studio in architectural education using sustainable development
}

\author{
Eray Bozkurt ${ }^{1 \mathrm{a}}$ \\ ${ }^{1}$ Yasar University, Department of Architecture, Selcuk Yasar Kampusü Bornova, İzmir, Turkey
}

\begin{abstract}
Sustainable development has been approved by many experts as the only suitable model for the growth of the next generation. Education has a valuable role to distribute sustainable approach to all subject fields like architecture. Sustainable development is gaining a central position in the conceptual framework of architectural education in universities. Universities are complex organizations that are frequently quite stable in the short term, but inevitably evolving over the longer term in response to changes in the societies. At the moment, there are various debates for changing non-renewable with more renewable and efficient architectural design strategies. Architectural Design has always attempted to merge the practicalities of engineering, technology, culture, and economy with the subtle elements of interface, social concerns and aesthetic desire. It has a crucial place for to engage with the sustainable strategies that provide countless environmental, economic, community, health and safety benefits. The education of the students about opportunities, risks, benefits and scientific knowledge of sustainable approach provide valuable contribution towards integral relationships. The theory lessons concentrate mainly on climate, thermal comfort, materials, and optimization of performance, environment and energy fields. Curriculum, knowledge and the teaching methods are connected with each other, especially on the search for the innovative ideas. As innovative ideas emerge, data available for the design process increases. However, such new data cannot be integrated to the design education as desired by current conventional teaching methods in a reliable context. At some points, this situation inhibits the creation of innovative ideas in architectural design. In order to acquire such data and to flourish a sustainable society accordingly, fast and efficient access to knowledge databases is needed. In this study, the research evaluates the current architectural education in Yasar University and suggests a proposal for the integration of theoretical courses and design studio under Sustainable Development.
\end{abstract}

Keywords: sustainable development; undergraduate; architecture; education; knowledge

${ }^{a}$ Corresponding author: eray.bozkurt@yasar.edu.tr 


\section{Introduction}

The concept of shelter first started with the erection of a single wall forward to protect the human body from excessive sunlight and wind conditions. Later on, there came an enclosure with other walls, roof and a chimney for the fire. The Industrial Revolution transformed this passive design method into a very complex set of schemes, which also caused cultural transformations. This change increased the energy dependence on fossil fuels and created massive environmental deteriorations. As a result, the previous simple understanding of the human body ignored for the human development. The conventional methods of building construction cause irreversible thread on the natural environment. Many recent researches indicate that the sustainable approach is the next development model for every industrial sector.

Architects have a large share of responsibility for reducing negative environmental impact and quantities of the required energy to inhabit and maintain buildings. The structures of buildings, their service arrangements, and their gradual adaptation use directly influence the nature of the impact on the environment. The evaluation of environmental measures is as important as issues of site planning, structure, services, spatial qualities and volumetric form. It is rather odd that architects do not seem to consider the subtle balance between buildings and climatic factors. It is probable that the technical issues of design work are believed as being more dominant than the spatially architectural aspects.

Education holds a valuable role to enhance the knowledge with the past experiences. Knowledge enters education systems from various topics and notions. This can be envisioned in the increased interest shown how knowledge participates in education. However, the teaching methods sometimes fail to achieve the desired improvements. The relationships between teaching and knowledge mainly focus on the access and teaching methods. With reference to the major elements of the regulatory role of education, access to knowledge is influenced by the rapid developments of the computer technology.

In the context of discourses about the knowledge-based society, sustainability-related productions have increased. Scientific discoveries, public utilities, product industries devoted their working principles towards the sustainable approach. The current conventional teaching and learning approaches may not be appropriate for addressing education for sustainability. New curriculum design, teaching methodology, and teacher training programs need to be updated to raise the extent of the sustainable thinking and cognition.

Architectural design has always undertaken to merge the practicalities of engineering, technology, culture, and thriftiness with the subtle elements of the interface, social concerns, and aesthetic desire. It possesses a crucial place for to engage with the sustainable strategies. Sustainable design approaches in architectural education, provide countless environmental, economic, community, health and safety benefits. It is outlined in terms of three key factors: ecological sustainability, economic sustainability, and socio-cultural sustainability. A global review of curricula in architecture and urban design indicates that the 'sustainable agenda' is beginning to assume a central position within higher education programs [1]. Many architectural education systems around the world have launched programs aiming to imply the sustainable development in the theoretical lessons and design studios.

\subsection{Outlook of architectural education}

Generally architectural education consists of two parts. The first part is the studio based design education where students explore their design projects and implement practical 
solutions with their theoretical background. The second part is the theoretical part, which improves the students' knowledge about the architectural discipline. Theoretical courses built up together from past experiences, for instance, the knowledge from the history of architecture, past references written on the subjects. All these knowledge transferred to students using the conventional methods. The conventional methods consist of the traditional room with a blackboard, and a PowerPoint presentation. Examination process based on the students abilities only in the exam period.

In worldwide conventional architectural educations, the design and theory courses evolve separately however the aim of the theory courses is to improve the perception and technical abilities of the students. The design studio's theme and approach take at least four weeks to motivate the students towards their design ideas. During that period, students observe the benefits of their chosen design form. However, theory courses in that four weeks can teach the technical issues in the classroom environments. With the consideration of the technology and changing society, the conventional teaching may fail to motivate the students in many ways. It is under discussion in many educational conferences and meetings.

The conventional teaching and learning approaches may not be appropriate for addressing architectural education for sustainability at the universities. New curriculum design, teaching methodology, and teacher training programs need to be updated to raise the extent of the sustainable thinking and knowledge. Recent project EDUCATE, funded in 2009 by the European Commission's Executive Agency for Competitiveness and Innovation under the Intelligent Energy Europe program, set to promote the integration of sustainability in the teaching and practice of architecture and urban design, offering guidelines and underlying support to curriculum development at pre and post-professional level. The survey revealed that more than $95 \%$ building professionals agreed that sustainable development should be included in the curricula of architectural education [1]. Sustainability workshop conducted at Istanbul Technical University in 2010, aimed to integrate the design project and sustainability. The results revealed that the students' awareness towards sustainable issues increased and 73 percent of the students improved their grades in comparison with their previous design project [11].

\section{Integral design approach}

The education of the students about opportunities, risks, benefits and scientific knowledge of sustainable approach provide valuable contribution towards integral relationships. The current lessons concentrate mainly on climate, thermal comfort, material use, environment and energy related theory ideas. The curriculum should implement creativity and encourage students to evaluate their works from different perspectives. As a teaching method, problem-based learning can be introduced and promote the application of tools and techniques for exploration of solutions appropriate to the various stages of design. The engagement students with external experts should start from the early stages of development of briefs and throughout the design process.

As innovative ideas emerge each day, data available for the design process increases. However, such new data cannot be integrated to the design education by current conventional methods in a reliable context. At some points, this situation inhibits the creation of innovative ideas in architectural design.

Sustainable development in building industry can only be achieved with the contributions of the architectural education. Mora et al. indicates that for integral life cycle building design, there is a need for more integrated treatment of buildings in research, education, and practice [6]. Mark De Kay in his book, shares his levels of complexity, which he argues arise from the unfolding sequence of development in human individuals, 
cultures and physical systems, which manifest as developmental sequences such as those for values, cognition, biological evolution, economic systems and world views [4].

The analysis of the conventional teaching will provide baseline to propose new curriculum ideas in architectural education. The current research aimed to analyze the current capabilities for supporting sustainable approach in architectural education in Yasar University. Then, it suggests new strategies in design education to trigger innovative thinking in sustainable development. The principal goals are to develop conceptions of the architectural education, consider possible teaching strategies, curriculum and learning outcome.

The proposal (Fig. 1) based on the ideas that close collaboration between studio and theory courses will provide many benefits for the growing attitude towards the sustainable development. In current conditions at Yasar University, design studio and theory courses examination processes are separated because there is not any close collaboration. The proposal suggests ways to create integration between the theory courses and design studio.

In the proposal, design studio divided into five modules (Fig. 1); site analysis, development of initial ideas, design tutorials, detailing and preparation for final presentation. During site analysis, design tutorials, and presentation period, the theory course can provide the necessary knowledge and technical abilities.

Studio course divided in two half days, one on a Tuesday afternoon and the other half on a Friday afternoon. There are four instructors in charge to observe students studio performance. Theory course is on Friday morning before the design studio. First half day, the studio instructors give individual table critiques to the students. The students and the instructors have discussions about the possibilities of design ideas, especially the form and its functions. The discussions continued over the sketch proposals of the students. After a while, material selection discussions begins and students prepares number of questions to be discussed in theory class.

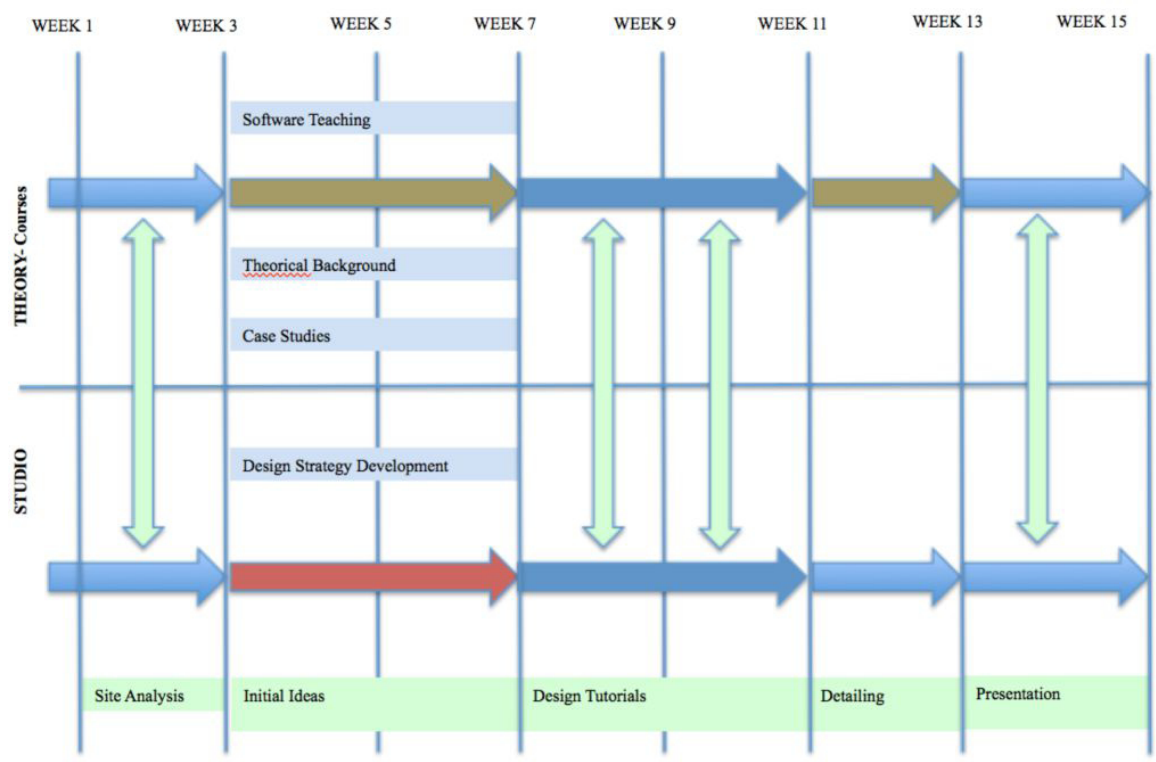

Fig 1. Integral studio and theory proposal 
Friday morning, theory class begins with a general description of the material selection process and the importance of the environmental protection. After a while, the students are required to work in groups to discuss their projects benefits or problems. The instructors have discussions with each student project. The theory course instructor overlooks the process and takes notes for the remainder of class discussions. In the final section of the class, all the instructors mention about the general failures of the projects to the invited expertise for the final revisions. Friday afternoon, the students will hold enough knowledge and feedback to finalize their design choice through discussions with their studio instructors.

In the proposal (Fig.1), first three weeks of the studio and theory courses will work together to analyze the project's site conditions in collaboration. From third week to seventh week, a theory will start the in-class discussions and provide general reference information to the students. Between fifth and 10th weeks, a theory will support the design studio's intentions with the sustainable approaches and teach necessary lectures to all of the pupils. After the 10th week, a theory will conduct lessons about the simulation programs. The students will present boards about their sustainable ideas in their projects.

The overall proposal suggests that:

- Close collaborations between the design studio and theory courses required and the design studio brief must be prepared at least three weeks before the semester.

- The role of the theory course is to contribute technical abilities to the design studio.

- The learning outcomes must be related to the sustainable development.

- Energy and environmental problems must be at the priority part of the design thinking.

- Technological developments should immediately take a part in the teaching methods.

- The changing society needs careful consideration and analysis for the future improvements in education.

\section{Conclusion}

In Yasar University's architectural education, the design studio and theory courses dealt separately, however, there are intentions to support the whole teaching process integration. In the third year level, general improvements observed in the performance of the students. There are now plans to distribute these benefits to all levels.

In architectural educations worldwide, the involvement of the technology triggered many new methods that can boost the performance of the instructors. The growing number of knowledge resources force education experts to debate new approaches. Besides these, the increasing environmental and energy problems lead to consider more sustainable approaches in architectural education. The research demonstrated that the integration of theory classes and design studio will improve the students' performances based on the correlated approach. A design studio and theory tutors should work in collaboration to make adequate discussions, and reach a mutual agreement with the learning outcomes.

\section{References}

1. Altomonte, S., Rutherford, P., \& Wilson, R. Mapping the Way Forward: Education for Sustainability in Architecture and Urban Design, 154(December 2012), 143-154. (2012). http://doi.org/10.1002/csr

2. Asce, Menzel, K., Hartkopf, V., \& Ilal, M., E. Collaborative Learning and Design in Architecture, Engineering, and Construction. In CINET2013 Conference Proceedings (pp. 309-337)., (2013). 
3. Blum, N., Nazir, J., Breiting, S., Goh, K. C., \& Pedretti, E. Balancing the tensions and meeting the conceptual challenges of education for sustainable development and climate change. Environmental Education Research, 19(2), 206-217., (2013). http://doi.org/10.1080/13504622.2013.780588

4. Fleming, R. Design Education for a Sustainable Future. New York: Routledge., (2013).

5. Jamieson, P., Fisher, K., Gilding, T., Taylor, P. G., \& Trevitt, a. C. F. Place and Space in the Design of New Learning Environments. Higher Education Research \& Development, 19(2), 221-236., (2000). http://doi.org/10.1080/072943600445664

6. Mora, R., Bitsuamlak, G., \& Horvat, M. Integrated life-cycle design of building enclosures. Building and Environment, 46(7), 1469-1479., (2011). http://doi.org/10.1016/j.buildenv.2011.01.018

7. Pavlova, M. Conceptualisation of technology education within the paradigm of sustainable development. International Journal of Technology and Design Education, 19(2), 109-132., (2009). http://doi.org/10.1007/s10798-008-9073-5

8. Talib, R. B., \& Sulieman, M. Z. (n.d.). Survey on Implementing Sustainable Issues into Interior Design Studios Project.

9. Van den Branden, K. Sustainable education: basic principles and strategic recommendations. School Effectiveness and School Improvement, 23(3), 285-304., (2012). http://doi.org/10.1080/09243453.2012.678865

10. Winter, C. Education for sustainable development and the secondary curriculum in English schools: rhetoric or reality? Cambridge Journal of Education, 37(3), 337-354., (2007). http://doi.org/10.1080/03057640701546656

11. Yazicioglu, F., \& Kus, H. Evaluating the Teaching of Sustainability Concepts in Detailed Design : A Case Study, (3), 69-86., (2011). 